\title{
A Novel Simplified Space-Vector Modulated Control Scheme for Three-Phase Switch-Mode Rectifier
}

\author{
Chern-Lin Chen, Che-Ming Lee, Rong-Jie Tu, and Guo-Kiang Horng \\ Power Electronics Laboratory \\ Department of Electrical Engineering \\ National Taiwan University \\ Taipei, Taiwan
}

\begin{abstract}
A novel simplified control scheme for threephase switch-mode rectifier is proposed in this paper. The proposed control scheme is based upon a load-conductance rectifier controller, in which reference current signals are obtained. The goal to follow the reference current is converted to follow a reference voltage. A simplified control scheme utilizing space-vector modulation is developed to calculate the duty ratio required to synthesize the reference voltage. The proposed scheme has the advantage of space-vector modulation with fast dynamic response, and being simple enough to be implemented in a low-cost microprocessor.
\end{abstract}

\section{INTRODUCTION}

Switch-mode rectifiers (SMRs) have gained increasing interests of research recently for improving power factor deterioration. A conventional three-phase boost-type SMR is consisted of six switches with antiparalleled diodes as shown in Fig. 1. This system is ideally applicable to DC-linked AC motor drives since it draws sinusoidal input currents, and controls the DC bus voltage. Moreover, its capability of bi-directional power flow allows regenerative operation, which is especially advantageous for high-power applications. The main drawback is that a more complicated control scheme and six corresponding driving circuits are required to control the six switches individually.

A simple hysteresis current control scheme for three-phase SMR is discussed in several papers $[1,2]$. The input phase current is individually controlled to track the corresponding template current waveform. It is capable of delivering nearly sinusoidal current waveforms with unity power factor. However, the switching pattern is random. This increases the switching losses and deteriorates the system performance.

Lately, the space-vector modulation method for three-phase SMR is proposed [3]. The input phase voltages are divided into six 60-degree intervals where no sign change occurs. Excellent power factor is obtained by controlling only two currents in each interval. The space-vector approach can provide fast dynamic control and stability, but is quite complicated to implement and require significant computational resources. High speed microprocessors or digital signal processors are required.
This paper presents a simplified space-vector modulated control scheme for three-phase SMR. In this control scheme, the reference current signals are obtained by load-conductance controller $[4,5]$. The goal to follow the reference current is converted to follow a reference voltage. A simplified control scheme utilizing space-vector modulation is developed to calculate the duty ratio required to synthesize the reference voltage. Experimental verification is carried using a low-cost microprocessor 80196MC. Experimental results with sinusoidal input current and nearly unity power factor are observed.

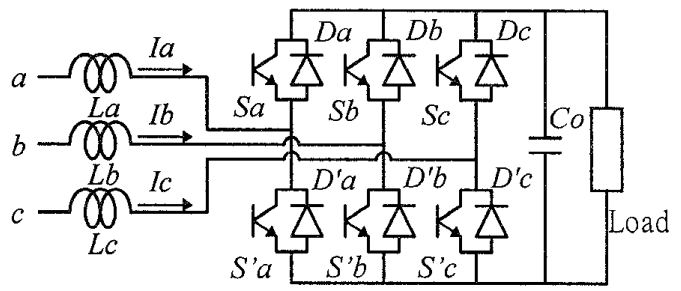

Fig. 1. Three-phase boost-type switch-mode rectifier

\section{PROPOSED SCHEME}

Fig. 2 illustrates the block diagram of the proposed control scheme. The power stage is six switches with anti-paralleled diodes as shown in Fig. 1.

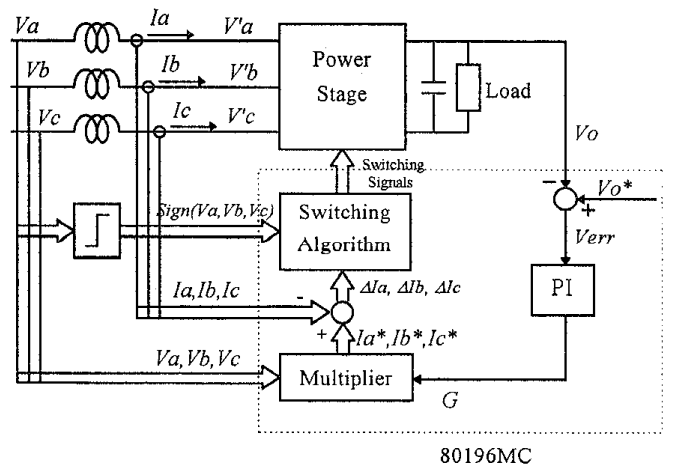

Fig. 2. Block diagram of the proposed control scheme 
The controller part (inside the dashed square) is accomplished using a low-cost microprocessor $80196 \mathrm{MC}$. The details of the proposed control scheme are explained as follows.

\section{A)Load Conductance Calculation}

The reference current signals are obtained based on the load conductance controller. The error between the reference and measured link capacitor voltage is processed through a PI controller. The output of the PI controller is defined as the rectifier load conductance $G$ $[4,5]$. The reference current signals are generated by the product of the load conductance and the input phase voltages. Therefore, if the input current is controlled to follow the current command, it follows the input voltage in its waveform and follow the load conductance in its magnitude.

\section{B)Model Development}

The input phase voltages can be divided into six 60 -degree intervals where no sign change occurs as shown in Fig. 3. Take interval I for example, $V a$ and $V b$ are positive, and $V c$ is negative. Since input currents are to be controlled to be in phase with input voltage, $I a$ and $I b$ are positive, and $I c$ is negative. In such condition, there will be no current flowing through $S a, S b, S^{\prime} c, D^{\prime} a, D^{\prime} b$, and $D c$. According to the states of $S^{\prime} a, S^{\prime} b$ and $S c$, there are eight operation modes, only four of which will be used in the proposed control scheme. Table I. illustrates the voltage vectors obtained in the four operation modes in interval I. The voltage vectors will be explained in the next section. Note that $S c$ is always set OFF in interval $I$, thus switching loss can be greatly reduced.

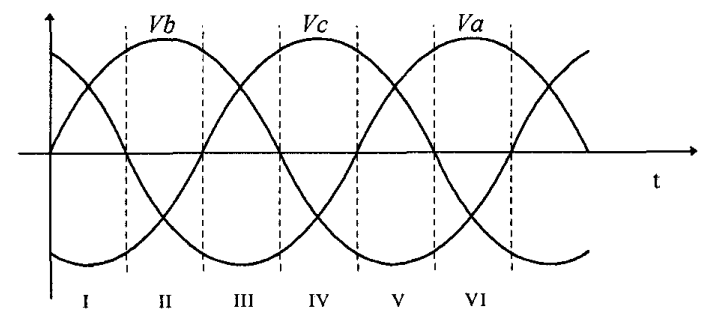

Fig. 3 Input phase voltages are divided into six 60-degree intervals

TABLE I

VOLTAGE VECTORS OBTAINED IN INTERVAL I

\begin{tabular}{|c|c|c|c|c|}
\hline & mode 1 & mode 2 & mode 3 & mode 4 \\
\hline$S c$ & $O F F$ & $O F F$ & $O F F$ & $O F F$ \\
\hline$S a^{\prime}$ & $O N$ & $O F F$ & $O N$ & $O F F$ \\
\hline$S b^{\prime}$ & $O N$ & $O N$ & $O F F$ & $O F F$ \\
\hline$V^{\prime} a$ & 0 & $2 V o / 3$ & $-V o / 3$ & $V o / 3$ \\
\hline$V^{\prime} b$ & 0 & $-V o / 3$ & $2 V_{o} / 3$ & $V o / 3$ \\
\hline$V^{\prime} c$ & 0 & $-V_{o} / 3$ & $-V o / 3$ & $-2 V_{o} / 3$ \\
\hline$V^{\prime}$ & 0 & $V o$ & $V o e^{j 2 \pi / 3}$ & $V o e^{j \pi / 3}$ \\
\hline
\end{tabular}

\section{C)Space-Vector Modulation}

With the concept of the space vector, it is convenient to represent three-phase quantities (voltages and currents) as a space vector:

$$
F=f a+f b \times \alpha+f c \times \alpha^{2}
$$

where $\alpha=e^{j 2 \pi / 3}$. Consequently, voltages before the rectifier bridge $V^{\prime} a, V^{\prime} b$, and $V^{\prime} c$ can be represented as a voltage vector $V^{\prime}$.

$$
V^{\prime}=V^{\prime} a+V^{\prime} b \times \alpha+V^{\prime} c \times \alpha^{2}
$$

According to the states of the six switches, there are seven voltage vectors as shown in Fig.4, where

$$
\begin{array}{ll}
V i=V o e^{j(i-1) \pi / 3} & \text { for } i=1 \ldots 6 \\
V i=0 & \text { for } i=0
\end{array}
$$

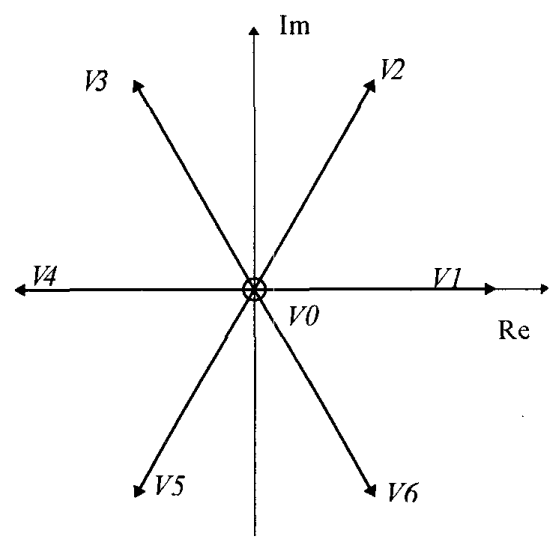

Fig. 4. Voltage vector representations of $V^{\prime} a, V^{\prime} b$, and $V^{\prime} C$

Also, the input phase voltages and currents can be represented as space vectors:

$$
\begin{gathered}
V=V a+V b \times \alpha+V c \times \alpha^{2} \\
I=I a+I b \times \alpha+I c \times \alpha^{2}
\end{gathered}
$$

From Fig. 2 the following equation can be obtained:

$$
\left(V-V^{\prime *}\right)=L \Delta I / \Delta T
$$

where $L=L a=L b=L c$ and $\Delta T$ is the switching period. Eq. (6) states that the current error vector is a function of the voltage vector $\mathrm{V}$ and $\mathrm{V}^{\prime}$ ' (i.e. the operation modes). The proper voltage vector command $V^{\prime *}$ can be decided according to the desired current error vectors $\Delta I$ and the input voltage vector $V$. Then the appropriate conducting states of the switches can be decided. For example, if $V^{\prime *}$ is located as shown in 
Fig. 5, it can be synthesized using V0 V1 and V2, which satisfies the following equations:

$$
\begin{aligned}
& \Delta T V^{\prime *}=T 0 V 0+T 1 V 1+T 2 V 2 \\
& T 0+T 1+T 2=\Delta T
\end{aligned}
$$

Eq. (7) and (8) can be solved to obtain the following:

$$
\begin{aligned}
\frac{T 1}{\Delta T} & =\frac{\left|V^{\prime} *\right| \cos \theta-\sqrt{3} / 3\left|V^{\prime} *\right| \sin \theta}{V o} \\
\frac{T 2}{\Delta T} & =\frac{2 \sqrt{2}\left|V^{\prime *}\right| \sin \theta}{V o} \\
T 0 & =\Delta T-T 1-T 2
\end{aligned}
$$

However, this algorithm requires complicated computations with complex numbers. A high speed microprocessor or digital signal processor must be used to encounter these computations.

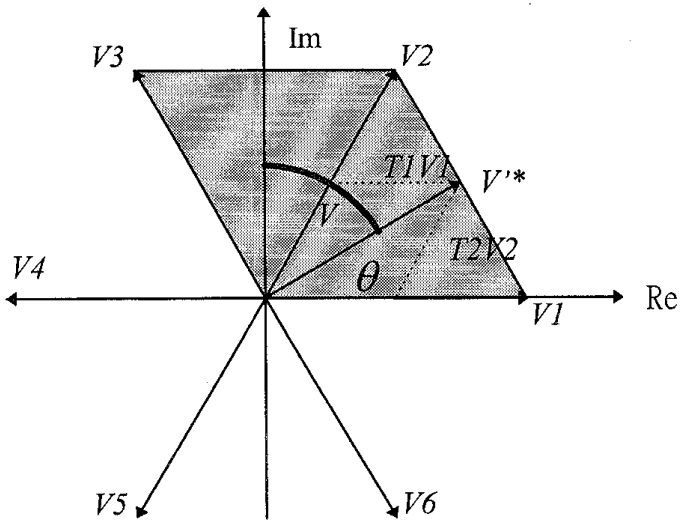

Fig. 5. Synthesis of voltage vector

\section{D)Simplified Control Scheme}

To make the space vector modulation scheme applicable in a low-cost microprocessor such as $80196 \mathrm{MC}$, the calculation process must be simplified. According to Table I, three voltage vector can be obtained in the four operation modes of interval I by just controlling two legs of the bridge. If $V^{\prime *}$ is located as in Fig. 5, by substituting the voltage values in Table I. into Eq. (7), the following equations can be obtained:

$$
\begin{aligned}
& \Delta T V a^{\prime *}=T 0 \times 0+T 1 \times \frac{2}{3} V o+T 2 \times \frac{1}{3} V_{o} \\
& \Delta T V b^{*}=T 0 \times 0+T 1 \times \frac{-1}{3} V o+T 2 \times \frac{1}{3} V_{O}
\end{aligned}
$$

Solving Eq. (12) and (13):

$$
\frac{T 1}{\Delta T}=\frac{V a^{*}-V b^{*}}{V o}
$$

$$
\frac{T 2}{\Delta T}=\frac{V a^{\prime *}+2 V b^{*}}{V o}
$$

$S a$ is on for $V I$ and $V 2$, and $S b$ is on for $V 2$. The duty ratio $D a$ and $D b$ of $S a$ and $S b$ thus can be obtained:

$$
\begin{aligned}
& D a=\frac{T 1}{\Delta T}+\frac{T 2}{\Delta T}=\frac{2 V a^{\prime *}+V b^{*}}{V o} \\
& D b=\frac{T 2}{\Delta T}=\frac{V a^{\prime *}+2 V b^{\prime *}}{V o}
\end{aligned}
$$

Note that in interval I, $V^{\prime *}$ will be located only in the shaded area in Fig. 5. If $V^{\prime *}$ is located where V0, V2 and V3 must be used to synthesize it, the duty ratio obtained will be exactly the same as eq. (16) and (17). Similarly, operations during the other intervals can be obtained as Table II. By using the simplified control scheme, the space vector modulation can be implemented in a low-cost microprocessor such as 80196MC.

TABLE II

DUTY RATIO OF THE SWITCHES IN THE SIX INTERVALS

\begin{tabular}{|c|c|}
\hline & duty ratio \\
\hline I & $D a=\left(2 V a^{\prime *}+V b^{\prime *}\right) / V O$ \\
& $D b=\left(V a^{\prime *}+2 V b^{\prime *}\right) / V O$ \\
\hline II & $D a=1+\left(2 V a^{\prime *}+V c^{\prime *}\right) / V O$ \\
& $D c=1+\left(V a^{\prime *}+2 V c^{\prime *}\right) / V_{O}$ \\
\hline III & $D b=\left(2 V b^{\prime *}+V c^{\prime *}\right) / V_{O}$ \\
& $D c=\left(V b^{\prime *}+2 V c^{\prime *}\right) V_{O}$ \\
\hline IV & $D a=1+\left(2 V a^{\prime *}+V b^{\prime *}\right) / V O$ \\
& $D b=1+\left(V a^{\prime *}+2 V b^{\prime *}\right) V_{O}$ \\
\hline V & $D a=\left(2 V a^{\prime *}+V c^{* *}\right) / V O$ \\
& $D c=\left(V a^{\prime *}+2 V c^{\prime *}\right) / V_{O}$ \\
\hline VI & $D b=1+\left(2 V b^{\prime *}+V c^{\prime *}\right) / V O$ \\
& $D c=1+\left(V b^{\prime *}+2 V c^{\prime *}\right) / V O$ \\
\hline
\end{tabular}

\section{Experimental Results}

A three-phase boost-type SMR with the proposed simplified control scheme is implemented and tested in the laboratory. The controller part is accomplished in a low-cost microprocessor 80196MC. A sinusoidal input current in phase with the corresponding input phase voltage is obtained as shown in Fig. 6. Fig.7 shows one of the gate driving signals and the input phase current. It is seen that the AC switch is set normally open in one third of the operation cycle. Therefore the switching losses are greatly reduced. 


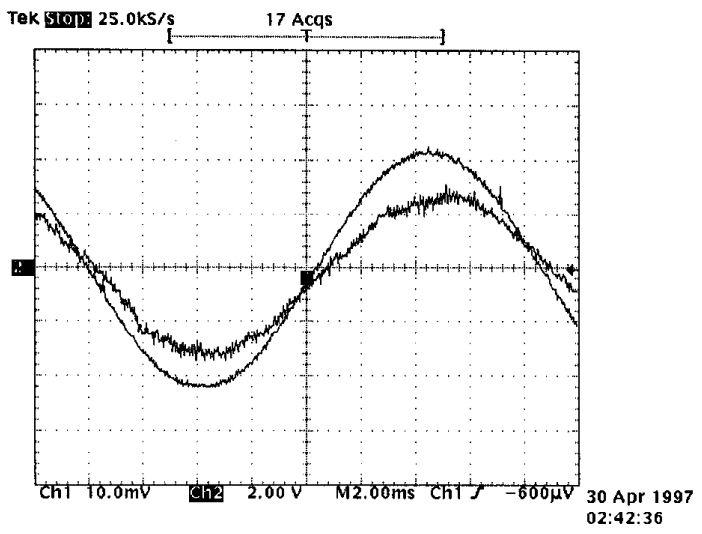

Fig. 6. Input phase voltage and current

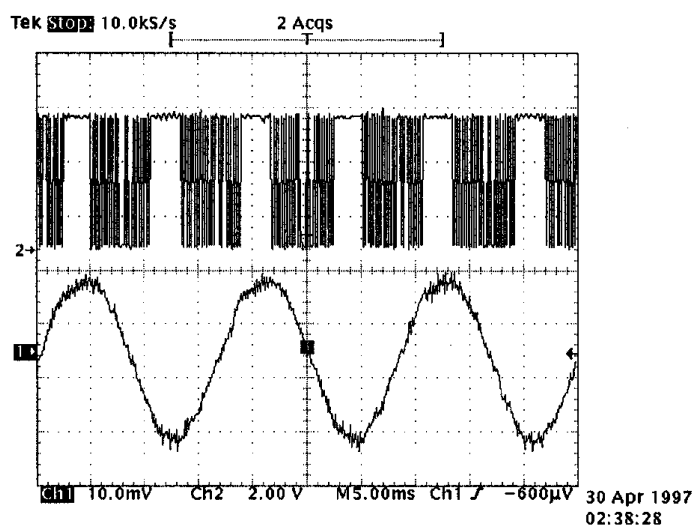

Fig. 7. One of the gate driving signals and the input current

\section{CONCLUSIONS}

This paper presents a novel simplified spacevector modulated control scheme for three-phase boosttype SMR. The main drawback of the circuit topology is the cost of the extra switches and driving circuits. Also, complicated control scheme is required. However, remarkable advantages are obtained using the proposed control scheme:

1) Employing the conventional three-phase boosttype SMR allows bi-directional power flow, which is very important in high power motor drive applications.

2) The six-switch module with anti-paralleled diodes is just the same as that used in the inverter, which is readily available.

3) Only two legs of the bridge are controlled in each operation interval. The overall switching power losses are greatly reduced.

4) The proposed control scheme utilizes the spacevector modulation technique, which has the advantage of fast dynamic response and stability.
5) The proposed control scheme simplifies the calculation process of the space-vector modulation, which makes it possible to be implemented in a low-cost microprocessor such as $80196 \mathrm{MC}$.

\section{REFERENCES}

[1] B.T. Ooi, J.C. Salmon, J.W. Dixon, and A.B. Kulkarni, "A 3phase controlled current converter with leading power factor," pp. 78-84, IEEE, Trans. Indus. Appl., Vol. IA-23, No. 1, 1987.

[2] J.W. Dixon, A.B. Kulkarni, M. Nishimoto, and B.T. Ooi "Characteristics of a controlled current PWM rectifier link," pp. 685-691, IEEE, IAS, Conference Proceeding, 1986

[3] R. Wu, S.B. Dewan, G.R. Slemon, "A PWM AC-to-DC converter with fixed switching frequency," pp. 880-885, IEEE, Trans. Indus. Appl, Vol. IA-26, No. 2, 1990.

[4] J. H. R. Enslin and J. D. Van Wyk, "A new control philosophy for power electronic converters as fictitious powe compensators," IEEE Trans. Power Electron., vol. 5, pp. 8897, Jan. 1990.

[5] S. Bhowmik, A. van Zyl, R. Spee, and J. H. R. Enslin "Sensorless current control for active rectifiers," IEEE Trans. Indus. Appli., vol. 33, no. 3, pp.765-772, May/June 1997. 